\title{
Anti-Toxoplasma activity of various molecular weights and concentrations of chitosan nanoparticles on tachyzoites of RH strain
}

This article was published in the following Dove Press journal: International Journal of Nanomedicine

\author{
Aref Teimouri ${ }^{1,2}$ \\ Sanaz Jafarpour Azami' \\ Hossein Keshavarz' \\ Fariba Esmaeili ${ }^{3}$ \\ Rasoul Alimi ${ }^{4}$ \\ Sara Ayazian Mavi' \\ Saeedeh Shojaee' \\ 'Department of Medical Parasitology \\ and Mycology, Tehran University \\ of Medical Sciences, Tehran, Iran; \\ ${ }^{2}$ Students Scientific Research Center, \\ Tehran University of Medical Sciences, \\ Tehran, Iran; ${ }^{3}$ Department of Medical \\ Nanotechnology, Tehran University \\ of Medical Sciences, Tehran, Iran; \\ ${ }^{4}$ Department of Epidemiology and \\ Biostatistics, School of Public Health, \\ Tehran University of Medical Sciences, \\ Tehran, Iran
}

Background: Natural polysaccharides such as chitosan (CS) are widely used as antimicrobial agents. In recent years, and considering that $\mathrm{CS}$ has a strong antimicrobial potential, interest has been focused on antimicrobial activity of chitosan nanoparticles (CS NPs). The main factors affecting the antibacterial activity of chitosan include molecular weight (MW) and concentration. In this regard, the aim of this study was to produce various MWs and concentrations of CS NPs, through the ionic gelation method, and investigate their potential anti-parasitic activity against tachyzoites of Toxoplasma gondii RH strain.

Materials and methods: The MWs and degree of deacetylation of the CS were characterized using viscometric and acid-base titration methods, respectively. The efficacy of various MWs and concentrations of NPs was assessed by performing in vitro experiments for tachyzoites of T. gondii RH strain, such as MTT assay, scanning electron microscopy, bioassay in mice and PCR. In vivo experiment was carried out in BALB/c mice which were inoculated with tachyzoites of $T$. gondii RH strain and treated with various MWs of CS NPs.

Results: The results of in vitro and in vivo experiments revealed that anti-Toxoplasma activity strengthened as the CS NPs concentration increased and the MW decreased. In vitro experiment showed $100 \%$ mortality of tachyzoites at 500 and 1,000 ppm concentrations of low molecular weight (LMW) CS NPs after $180 \mathrm{~min}$ and at 2,000 ppm after $120 \mathrm{~min}$. Furthermore, a 100\% mortality of tachyzoites was observed at 1,000 and 2,000 ppm concentrations of medium molecular weight (MMW) CS NPs and at 2,000 ppm concentration of high molecular weight (HMW) CS NPs after $180 \mathrm{~min}$. Growth inhibition rates of tachyzoites in peritoneal exudates of mice receiving low, medium and high MWs of CS NPs were found to be $86 \%, 84 \%$ and $79 \%$ respectively, compared to those of mice in sulfadiazine treatment group (positive control).

Conclusion: Various MWs of CS NPs exhibited great anti-Toxoplasma efficiency against tachyzoites of RH strain, with the greatest efficacy shown by LMW CS NPs in both experiments. It seems that CS NPs can be used as an alternative natural medicine in the treatment of toxoplasmosis. Keywords: chitosan nanoparticles, molecular weights, Toxoplasma gondii RH strain, degree of deacetylation

\section{Introduction}

Toxoplasma gondii, an obligate intracellular protozoan with worldwide distribution, is the agent of toxoplasmosis in humans and animals. ${ }^{1}$ Toxoplasmosis can be transmitted by tissue cysts through the eating of raw or undercooked meat and by sporulated oocysts from ingestion of infected vegetables and water. Congenital infection is possible by vertical transmission of tachyzoites during pregnancy. ${ }^{2}$ Acute infection is usually benign with self-limiting adenopathy in immunocompetent individuals but is dangerous
Department of Medical Parasitology and Mycology, School of Public Health, Tehran University of Medical Sciences, Pour Sina Street, Ghods Avenue, Enghelab Avenue, Tehran 1417613191 , Iran

Tel/fax +9821 8895 I392

Email shojaee1980@yahoo.com 
in pregnant women and patients with immunodeficiency. ${ }^{3-5}$ Treatment is based on combination of pyrimethamine and sulfadiazine. Despite rapid and great efficiencies of the available drugs, frequent toxic side effects are the major limitations for the use of these drugs. ${ }^{6}$ Some of these side effects include hematologic toxicity, allergy, folic acid deficiency and bone marrow suppression.

Nowadays, nanotechnology is widely used in different fields of science. In particular, nanoparticles (NPs) have attracted significant attentions as anti-parasitic agents in recent years. ${ }^{7}$ Inorganic NPs can be used as antimicrobial agents in various fields, especially food-packaging sectors. As mentioned previously, antimicrobial activity of inorganic NPs can cover a broad spectrum of microorganisms including foodborne pathogens. ${ }^{8}$ NPs of various sizes can be used in for in vitro and in vivo studies on parasites. These studies are mainly motivated by their use in the treatment of various diseases. ${ }^{9,10}$ Synthesis of NPs, especially natural polysaccharide NPs, has been of high interest among the researchers owing to their biodegradation, hydrophobicity and biocompatibility properties as well as good stability. ${ }^{11}$ Chitosan (CS) is a natural polysaccharide resulting from deacetylation of chitin in alkaline conditions and is composed of N-acetylD-glucosamine and D-glucosamine units. In addition to its harmless nature, CS includes striking properties such as antibacterial, antitumor and antifungal properties as well as abilities to heal wounds and stimulate the immune system. ${ }^{12,13}$ Chitosan nanoparticles (CS NPs) are a promising system for drug deliveries, including ocular and brain drug deliveries, oral administration of drugs and vaccine deliveries. ${ }^{14}$ Several factors that affect the antibacterial activity of CS include the environmental conditions such as $\mathrm{pH}$, type of microorganism and neighboring components, and the structural conditions such as concentration, degree of polymerization (DP) or MW, degree of deacetylation (DD) and derivative form as well as the original source of CS. ${ }^{15}$ Studies on antimicrobial activity of CS have been carried out in different conditions with conflicting results. ${ }^{16-19}$ Low molecular weight (LMW) CS has been shown to have the strongest effect in bacterial growth reduction compared with other MWs (medium [MMW] and high [HMW]) of CS. ${ }^{12,16-18}$ To the best of our knowledge, no study has been conducted on determining the effects of various MWs of CS NPs on T. gondii tachyzoites. In this regard, the aim of this study was to produce various MWs and concentrations of CS NPs, through the ionic gelation method. Then, the effects of three MWs and concentrations of CS NPs were investigated against tachyzoites of $T$. gondii $\mathrm{RH}$ strain in both in vitro and in vivo experiments.

\section{Materials and methods}

\section{Animals}

Six-week-old female BALB/c mice weighing 20-25 g were used in the current study. Animals were kept under standard laboratory conditions (light-dark cycle situation, controlled temperatures of $22^{\circ} \mathrm{C} \pm 2{ }^{\circ} \mathrm{C}$ ) with ad libitum food and water supplies. The study was approved by the Ethics Committee of Tehran University of Medical Sciences, Tehran, Iran (Approval No. 33436). Animal experiments were done according to Guide for the Care and Use of Laboratory Animals published by the United States National Institutes of Health and approved by the Ethical Committee of Tehran University of Medical Sciences for the use of laboratory animals.

\section{Parasites}

Tachyzoites of $T$. gondii RH strain were passaged in BALB/c mice using intraperitoneal (IP) serial passages. ${ }^{20}$ Tachyzoites were collected from peritoneal cavity of the infected mice, washed with phosphate-buffered saline (PBS pH 7.4) and counted using a hemocytometer slide. Concentrations of $1.5 \times 10^{6}$ and $1 \times 10^{4}$ tachyzoites per $0.5 \mathrm{~mL}$ of sterile PBS were selected for in vitro and in vivo challenges, respectively, and inoculated into mice peritoneum.

\section{Chitosan}

Various MWs of commercial CS including LMW (MW 50-190 kDa with 75\%-85\% deacetylated, Cat No. 448869-50G), MMW (MW 190-310 kDa with 75\%-85\% deacetylated, Cat No. 448877-50G) and HMW (MW 310-375 kDa with $>75 \%$ deacetylated, Cat No 419419-50G) were purchased from Sigma-Aldrich Co. (St Louis, MO, USA) for this study.

\section{Characterization of CS}

\section{Determination of degree of deacetylation}

The DD of the commercial CS samples was determined by an acid-base titration method. In this method, $0.3 \mathrm{~g}$ of commercial $\mathrm{CS}$ was dissolved in $30 \mathrm{~mL}$ of $0.1 \mathrm{M} \mathrm{HCl}$ at $20^{\circ} \mathrm{C} \pm 5^{\circ} \mathrm{C}$ with stirring in a $250 \mathrm{~mL}$ flask, and then $2-3$ drops of methyl orange indicator were added to the solution. Then, the solution was titrated using $0.1 \mathrm{M} \mathrm{NaOH}$. At the final point of the titration, color changed from pink to orange yellow which was verified using $\mathrm{pH}$ meter. To calculate water content, $0.5 \mathrm{~g}$ of CS was heated at $105^{\circ} \mathrm{C}$ until a constant weight was reached. The proportion of free $\mathrm{NH}_{2}$ groups in CS was calculated as follows: ${ }^{21}$

$$
\mathrm{NH}_{2}(\%)=\frac{\left(\mathrm{C}_{1} \mathrm{~V}_{1}-\mathrm{C}_{2} \mathrm{~V}_{2}\right) \times 0.016}{\mathrm{G}(100-\mathrm{W})} \times 100 \%
$$




$$
\text { Free } \mathrm{NH}_{2}(\%)=\frac{\mathrm{NH}_{2}(\%)}{9.94 \%} \times 100 \%
$$

where $\mathrm{C}_{1}$ is the concentration of $\mathrm{HCl}(\mathrm{M}), \mathrm{C}_{2}$ the concentration of $\mathrm{NaOH}(\mathrm{M}), \mathrm{V}_{1}$ the volume of $\mathrm{HCl}$ added $(\mathrm{mL})$, $\mathrm{V}_{2}$ the volume of $\mathrm{NaOH}$ added by titration $(\mathrm{mL}), \mathrm{G}$ the sample weight $(\mathrm{g}), \mathrm{W}$ the water percentage of sample (\%) and 0.016 the weight of $\mathrm{NH}_{2}$ equal to $1 \mathrm{~mL} 0.1 \mathrm{M} \mathrm{HCl}(\mathrm{g}) ; 9.94 \%$ is the theoretical $\mathrm{NH}_{2}$ percentage of $\mathrm{CS}$.

\section{Molecular weight determination}

The average MW of the commercial CS samples was determined by viscometric method. Five concentrations of CS solutions were prepared using the solvent system of $0.1 \mathrm{M}$ acetic acid and $0.2 \mathrm{M} \mathrm{NaCl}(1: 1, \mathrm{v} / \mathrm{v})$. The efflux time of the solutions was calculated in triplicate using Ubbelohde capillary viscometer at $25^{\circ} \mathrm{C}$. Solution and solvent running times were recorded in seconds and used to calculate intrinsic viscosity. The viscosity $(M v)$ was calculated using MarkHouwink equation $[\eta]=K M v^{\alpha}$, where $[\eta]$ determined the intrinsic viscosity, and $K$ and $\alpha$ are constants of the values that depend on the nature of polymers and solvents as well as temperatures and DD. Values of $K$ and $\alpha$ were calculated as $1.64 \times 10^{-30} \times \mathrm{DD}^{14}(\mathrm{~mL} / \mathrm{g})$ and $-1.02 \times 10^{-2} \times \mathrm{DD}+1.82$, respectively, where $\mathrm{DD}$ is the degree of deacetylation of CS expressed as percentage. ${ }^{22}$

\section{Preparation of nanoparticles}

CS NPs were prepared using ionic gelation method as previously described. ${ }^{23}$ Various MWs of CS were dissolved in $1 \%$ acetic acid and stirred overnight at room temperature. Tripolyphosphate (TPP) was dissolved in double-distilled water at a concentration of $0.05 \% \mathrm{w} / \mathrm{v}$. CS NPs were prepared by dropwise addition of TPP solution to CS solution (1:5 ratio) using an insulin syringe. The solution was stirred at room temperature. To reduce the size of NPs, ultrasonication was carried out for $5 \mathrm{~min}$. Size of the particles was calculated using dynamic light scattering method.

\section{In vitro experiment}

The anti-Toxoplasma efficiency of three concentrations (500, 1,000 and 2,000 ppm) of CS NPs with various MWs was assessed for 30, 60, 120 and $180 \mathrm{~min}$. For in vitro experiments, $0.5 \mathrm{~mL}$ of each concentration of CS NPs with various MWs was added to $1.5 \times 10^{6}$ fresh tachyzoites in sterile test tubes. The content of each tube was gently mixed and then incubated at $37^{\circ} \mathrm{C}$ for $30,60,120$ and $180 \mathrm{~min}$. After incubation, viable tachyzoites were calculated using methylene blue stain and light microscopy. Control tubes contained tachyzoites and normal saline with $1 \%(\mathrm{w} / \mathrm{v})$ acetic acid. Experiments were carried out in triplicate, and the mean and standard deviation (SD) were calculated for each sample. After the incubation time, $200 \mu \mathrm{L}$ of each suspension was used for the MTT assay.

\section{Cell viability assay}

To estimate the viability rate of tachyzoites of $T$. gondii RH strain in various concentrations of CS NPs with various MWs, MTT assay was carried out according to the manufacturer's instructions. Briefly, $10 \mu \mathrm{L}$ of MTT (Bio-Idea Co, Tehran, Iran) was added to the test and control tachyzoites and incubated at $37^{\circ} \mathrm{C}$ for $4 \mathrm{~h}$ with $5 \% \mathrm{CO}_{2}$. Then, $50 \mu \mathrm{L}$ of dimethyl sulfoxide solution (Merck KGaA, Darmstadt, Germany) was added to the mixtures to dissolve the formazan crystals. Absorbance intensity was calculated at $630 \mathrm{~nm}$ using automated ELISA reader (LX800; Biotec, Winooski, VA, USA). The nonviable microorganisms were calculated using the following equation:

Nonviable microorganisms $(\%)=100-\frac{\mathrm{AT}-\mathrm{AB}}{\mathrm{AC}-\mathrm{AB}} \times 100$

where $\mathrm{AT}$ is the OD of treated well, $\mathrm{AB}$ is the OD of blank well and $\mathrm{AC}$ is the OD of negative control. ${ }^{24}$ Negative control wells received no treatments and blank wells contained just the media. Mean and SD of the triplicate experiments were reported for each sample.

\section{Bioassay}

Concentrations of CS NPs showing $100 \%$ mortality rates in in vitro assay were selected for bioassay. Treated tachyzoites were inoculated into the peritoneum of mice $(n=3)$. At the same time, control tachyzoites (in normal saline containing $1 \%$ acetic acid) were inoculated into mice peritoneum as a control. After 5 days of inoculation, peritoneal exudates were collected and examined for tachyzoites using light microscopy. Morbidity and mortality rates in animals were monitored daily up to 2 months. Then, the inoculated mice were sacrificed for the detection of $T$. gondii cysts in brain tissues and further assessments using light microscopy and PCR.

\section{Detection of tissue cysts by PCR}

PCR assay was carried out for detection of $T$. gondii DNA in the brain of mice inoculated with CS NPs treated tachyzoites. Briefly, DNA was extracted from the brain 
tissue using Qiagen Amp DNA Mini Kit (Qiagen NV, Venlo, the Netherlands) according to the manufacturer's instructions. The B1 gene was amplified using two sets of primers, including B1ToxoF: 5'-GGAACTGCATCCGTTCATGAG-3' and B1ToxR: 5'-TCTTTAAAGCGTTCGTGGTC-3', resulting in $200 \mathrm{bp}$ amplicons. ${ }^{25}$ Amplicons were analyzed using $1 \%$ agarose gel containing Safe stain and visualized under UV illumination.

\section{Scanning electron microscopy (SEM) of tachyzoites}

After $2 \mathrm{~h}$ of exposure to CS NPs, tachyzoites were attached on coverslips and fixed in a solution containing $2 \%$ paraformaldehyde and $2.5 \%$ glutaraldehyde in $0.1 \mathrm{M}$ sodium cacodylate buffer ( $\mathrm{pH}$ 7.4). After fixation, cells were washed in cacodylate buffer and post-fixed using 1\%-2\% osmium tetroxide in $0.1 \mathrm{M}$ phosphate buffer $(\mathrm{pH} 7.2)$ for $2-4 \mathrm{~h}$ at room temperature. Then, all samples were dehydrated in graded ethanol dilutions $\left(70,80,90\right.$ and $\left.100^{\circ} \%\right)$. Cells were dried using critical point method, mounted on stubs, coated with gold (20-30 nm) and then observed using SEM.

\section{In vivo experiment}

Twenty-five female BALB/c mice were infected using IP inoculation of $1 \times 10^{4}$ tachyzoites of $T$. gondii $\mathrm{RH}$ strain and were then equally divided into five groups. Treatment was given $4 \mathrm{~h}$ after inoculation for 5 days on a daily basis as follows: 1) $0.2 \mathrm{~mL}$ LMW CS NPs by IP infusion; 2) $0.2 \mathrm{~mL}$ MMW CS NPs by IP infusion; 3) $0.2 \mathrm{~mL}$ HMW CS NPs by IP infusion; 4) $400 \mathrm{mg} / \mathrm{L} /$ day of sulfadiazine in drinking water (positive control group); and 5) $0.2 \mathrm{~mL}$ of normal saline containing $1 \%$ acetic acid by IP infusion (negative control group). ${ }^{26}$ Mice were monitored daily and the mortality rate was recorded for each group. On day 5 of the treatment, mice peritoneal fluids were collected and tachyzoites were counted using light microscopy.

\section{Statistical analysis}

Statistical analysis was carried out using SPSS Software version 20 (IBM Corporation, Armonk, NY, USA). Statistical differences between the test and control groups were analyzed using one-way analysis of variance (ANOVA) with a confidence interval of $95 \%$. The Bonferroni/Tukey test was used as post hoc test for multiple comparisons. The KaplanMeier method was used to compare the survival times of the studied groups in the acute phase of toxoplasmosis. ${ }^{27}$ The $P$-values $\leq 0.05$ were considered statistically significant.

\section{Results Characterization of CS}

The characteristics and particle sizes of CS with various MWs are presented in Table 1.

\section{In vitro experiments}

Anti-Toxoplasma activity of various MWs and concentrations of CS NPs

Results of in vitro anti-Toxoplasma activity of various MWs and concentrations of CS NPs are summarized in Table 2. Results showed that the anti-Toxoplasma effect strengthened as the CS NPs concentration increased. The greatest mean of mortality of tachyzoites was seen after $180 \mathrm{~min}$ and for 2,000 ppm concentration of LMW CS NPs (Figures 1 and 2). Furthermore, results indicated that the anti-Toxoplasma activity increased as the MW decreased. One-hundred percent mortality was observed only at 500 and 2,000 ppm concentrations of LMW CS NPs after 180 and 120 min, respectively. The anti-Toxoplasma effect of CS NPs with various MWs was statistically significant in the test group at all tested times ( $P<0.05)$, compared to that in the negative control group. There were no statistically significant differences in the antiToxoplasma activity at various MWs of CS NPs.

\section{MTT analysis}

The MTT assay results are summarized in Table 3. The results of MTT assay were associated with the results of methylene blue stain. According to the results, the antiToxoplasma activity of CS NPs with various MWs was significant in the test group at all exposure times $(P<0.05)$, compared to that in control group.

\section{Bioassay}

Peritoneal exudates were collected from the mice after 5 days of inoculation with treated tachyzoites. No tachyzoites were seen in these samples. No signs of acute infection were observed after 2 months of inoculation. Then, the animals

Table I Physicochemical properties and particle sizes of commercial CS with various MWs

\begin{tabular}{llll}
\hline $\begin{array}{l}\text { Various MWs } \\
\text { of CS }\end{array}$ & $\begin{array}{l}\text { Deacetylation } \\
\text { degree (\%) }\end{array}$ & $\begin{array}{l}\text { Molecular } \\
\text { weight (kDa) }\end{array}$ & $\begin{array}{l}\text { Particle } \\
\text { size (nm) }\end{array}$ \\
\hline LMW & $82 \pm 0.6$ & $86 \pm 4.1$ & $200-400$ \\
MMW & $76 \pm 0.8$ & $234 \pm 5.5$ & $200-400$ \\
HMW & $68 \pm 0.5$ & $353 \pm 6.2$ & $200-400$ \\
\hline
\end{tabular}

Note: Values are represented as mean \pm SD.

Abbreviations: MWs, molecular weights; CS, chitosan; LMW, low molecular weight; MMW, medium molecular weight; $\mathrm{HMW}$, high molecular weight. 
Table 2 In vitro effects of various MWs and concentrations of CS NPs on mortality of T. gondii tachyzoites using methylene blue stain

\begin{tabular}{|c|c|c|c|c|c|c|}
\hline \multirow{4}{*}{$\begin{array}{l}\text { MW of } \\
\text { CS NPs }\end{array}$} & \multirow[t]{4}{*}{ Concentration } & \multicolumn{4}{|l|}{ Time (min) } & \multirow[t]{4}{*}{$\overline{P \text {-value }}$} \\
\hline & & 30 & 60 & 120 & 180 & \\
\hline & & Mean mortality & Mean mortality & Mean mortality & Mean mortality & \\
\hline & & \pm SD & \pm SD & $\pm \mathbf{S D}$ & \pm SD & \\
\hline LMW & \multirow[t]{3}{*}{500 ppm (0.05\%) } & $31.7 \pm 1.5$ & $50.5 \pm 1.8$ & $81.1 \pm 2.2$ & $100 \pm 0.0$ & \multirow[t]{3}{*}{$0.016^{*}$} \\
\hline MMW & & $29.4 \pm 1.1$ & $39.6 \pm 1.2$ & $85.5 \pm 1.2$ & $99.4 \pm 1.04$ & \\
\hline HMW & & $27.5 \pm 1.1$ & $40.1 \pm 1.4$ & $55.3 \pm 1.9$ & $70.6 \pm 1.2$ & \\
\hline LMW & \multirow[t]{3}{*}{ I,000 ppm (0.1\%) } & $50 \pm 1.5$ & $65.5 \pm 2.3$ & $90.5 \pm 2.4$ & $100 \pm 0.0$ & \multirow[t]{3}{*}{$0.005^{*}$} \\
\hline MMW & & $29.2 \pm 1.2$ & $50.4 \pm 0.8$ & $86.3 \pm 0.9$ & $100 \pm 0.0$ & \\
\hline HMW & & $29.7 \pm 1.2$ & $50 \pm 0.6$ & $76.3 \pm 0.9$ & $85.9 \pm 2.8$ & \\
\hline LMW & \multirow[t]{4}{*}{2,000 ppm (0.2\%) } & $67.3 \pm 2.9$ & $83.8 \pm 2.4$ & $100 \pm 0.0$ & $100 \pm 0.0$ & \multirow[t]{4}{*}{$0.002^{*}$} \\
\hline MMW & & $31.8 \pm 1.1$ & $52.9 \pm 1.2$ & $89.5 \pm 1.5$ & $100 \pm 0.0$ & \\
\hline HMW & & $30.5 \pm 1.1$ & $52.9 \pm 1.2$ & $89.5 \pm 1.5$ & $100 \pm 0.0$ & \\
\hline NC & & $1.0 \pm 0.0$ & $2.0 \pm 0.0$ & $7 \pm 1.7$ & $9.3 \pm 1.1$ & \\
\hline
\end{tabular}

Notes: The proportion of nonviable tachyzoites was calculated using hemocytometer slide after adding various MWs of CS NPs and staining with methylene blue. The mortality rates were calculated using numbers of parasites in test and control groups. Values are given as the mean \pm SD of three experiments. *Significant at $P<0.05$; NC, negative control of normal saline with $1 \%(w / v)$ acetic acid.

Abbreviations: MWs, molecular weights; CS NPs, chitosan nanoparticles; LMW, low molecular weight; MMW, medium molecular weight; HMW, high molecular weight; NC, negative control; SD, standard deviation; T. gondii, Toxoplasma gondii.

were sacrificed to investigate the presence of cysts in the brain tissues. No cysts were found in the brain tissues of the mice. In control mice, infection signs appeared after 4 days and all mice died after 7 days of inoculation. Peritoneal exudates of control mice contained a greater number of tachyzoites at day 5 of inoculation.

\section{PCR assay}

The B1 gene was amplified for the detection of tissue cysts in mice brain. Cysts were detected in the brain tissue of positive

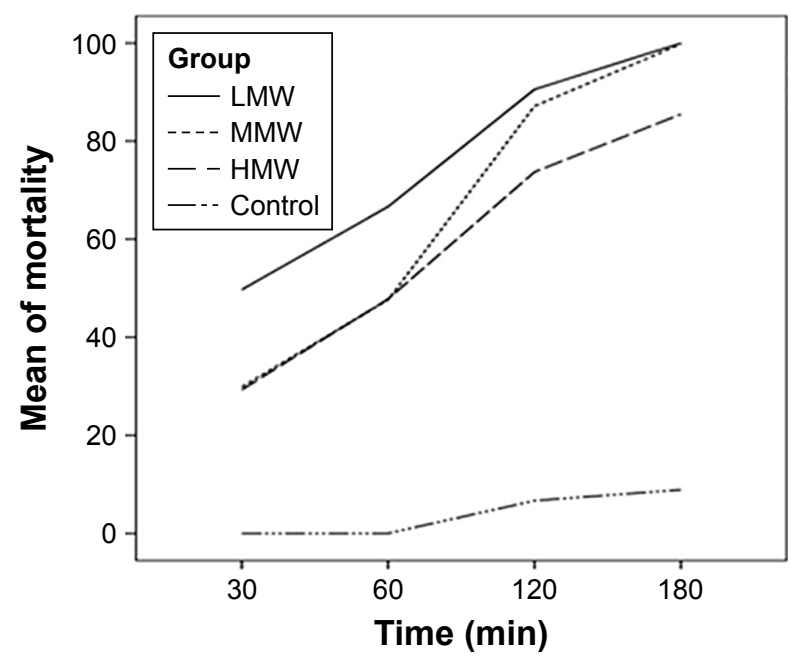

Figure I Effects of various incubation times of CS NPs with various MWs on the mean of mortality rate of $T$. gondii RH strain tachyzoites.

Abbreviations: MWs, molecular weights; CS NPs, chitosan nanoparticles; LMW, low molecular weight; MMW, medium molecular weight; HMW, high molecular weight; T. gondii, Toxoplasma gondii. control mice, whereas no cysts were detected in the brain tissues of mice inoculated with treated tachyzoites.

\section{Morphological and ultrastructural analyses of treated T. gondii tachyzoites}

SEM was used to investigate the morphological changes in tachyzoites treated with 2,000 ppm of LMW CS NPs. Normal morphology was seen in untreated tachyzoites (Figure 3A, C and $\mathrm{E}$ ), with stable cell surfaces and typical crescent shapes with obvious conoid. In contrast, tachyzoites treated with CS

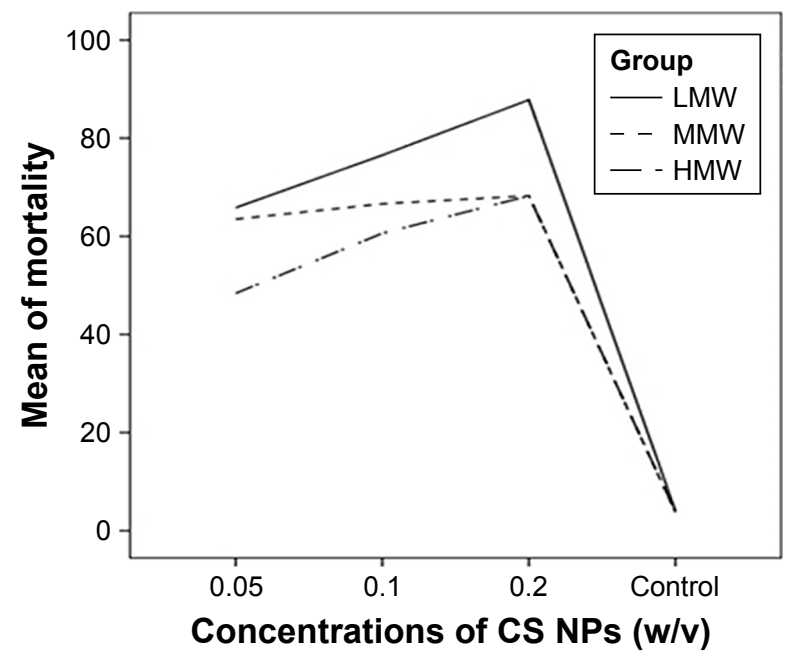

Figure 2 Effects of various concentrations of CS NPs with various MWs on the mean of mortality rate of $T$. gondii $\mathrm{RH}$ strain tachyzoites.

Abbreviations: MWs, molecular weights; CS NPs, chitosan nanoparticles; LMW, low molecular weight; MMW, medium molecular weight; HMW, high molecular weight; T. gondii, Toxoplasma gondii. 
Table 3 In vitro effects of various MWs and concentrations of CS NPs on the mortality rate of $T$. gondii RH strain tachyzoites using MTT assay

\begin{tabular}{|c|c|c|c|c|c|c|}
\hline \multirow{3}{*}{$\begin{array}{l}\text { MW of } \\
\text { CS NPs }\end{array}$} & \multirow[t]{3}{*}{ Concentration } & \multicolumn{4}{|l|}{ Time (min) } & \multirow[t]{3}{*}{$P$-value } \\
\hline & & 30 & 60 & 120 & 180 & \\
\hline & & $\begin{array}{l}\text { Mean mortality } \\
\pm \text { SD }\end{array}$ & $\begin{array}{l}\text { Mean mortality } \\
\pm \text { SD }\end{array}$ & $\begin{array}{l}\text { Mean mortality } \\
\pm \text { SD }\end{array}$ & $\begin{array}{l}\text { Mean mortality } \\
\pm \text { SD }\end{array}$ & \\
\hline LMW & \multirow[t]{3}{*}{500 ppm (0.05\%) } & $27.9 \pm 1.2$ & $45.1 \pm 1.4$ & $78.8 \pm 3$ & $100 \pm 0.0$ & \multirow[t]{3}{*}{$0.023^{*}$} \\
\hline MMW & & $25.9 \pm 1.4$ & $37.1 \pm 2.5$ & $8 I .1 \pm 3.1$ & $98.7 \pm 1.1$ & \\
\hline HMW & & $24.4 \pm 1.7$ & $37.3 \pm 2.5$ & $54 \pm 2.7$ & $69.2 \pm 3$ & \\
\hline LMW & \multirow[t]{3}{*}{ I,000 ppm (0.1\%) } & $45.3 \pm 2.8$ & $60.3 \pm 1.9$ & $87.1 \pm 2.7$ & $100 \pm 0.0$ & \multirow[t]{3}{*}{$0.006 *$} \\
\hline MMW & & $28 \pm 1.9$ & $46.7 \pm 2.2$ & $83.3 \pm 2.9$ & $100 \pm 0.0$ & \\
\hline HMW & & $26.7 \pm 2.1$ & $48.8 \pm 1.2$ & $71.8 \pm 1.9$ & $84 \pm 2.1$ & \\
\hline LMW & \multirow[t]{4}{*}{2,000 ppm (0.2\%) } & $62.8 \pm 3.3$ & $81.37 \pm 1.3$ & $98.3 \pm 1.5$ & $100 \pm 0.0$ & \multirow[t]{4}{*}{$0.002 *$} \\
\hline MMW & & $30.1 \pm 1$ & $52.2 \pm 2.3$ & $85.9 \pm 2.2$ & $100 \pm 0.0$ & \\
\hline HMW & & $29.1 \pm 2.5$ & $50.8 \pm 2.3$ & $86.4 \pm 1.5$ & $100 \pm 0.0$ & \\
\hline NC & & $0.0 \pm 0.0$ & $0.0 \pm 0.0$ & $4.6 \pm 0.5$ & $8 \pm 2$ & \\
\hline
\end{tabular}

Notes: Values are given as the mean $\pm \mathrm{SD}$; *Significant at $P<0.05 ; \mathrm{NC}$, negative control of normal saline containing $1 \%(\mathrm{w} / \mathrm{v})$ acetic acid.

Abbreviations: MWs, molecular weights; CS NPs, chitosan nanoparticles; LMW, low molecular weight; MMW, medium molecular weight; HMW, high molecular weight; NC, negative control; SD, standard deviation; T. gondii, Toxoplasma gondii.

NPs showed clear morphological changes, such as multiple deep ridges on the surface and irregular surface protrusions (Figure 3B, D and F).

\section{In vivo experiments}

In in vivo experiment, the effects of various MWs of CS NPs on survival time of mice were assessed. The mean survival time in all the groups treated with various MWs of CS NPs was longer than that in the negative control group (Table 4). In the control group, infection signs appeared after day 4 and mice died within 4-6 days of inoculation. Although various MWs of CS NPs increased the survival time of mice in the test group compared to that in the negative control group, differences were statistically significant between the survival of mice treated with LMW CS NPs and survival of mice in negative control group $(P=0.009)$. In mice treated with LMW CS NPs, the survival time extended from 6 to 8 days after inoculation (Figure 4).

Anti-Toxoplasma effects of various MWs of CS NPs in mice peritoneal exudates are described in Table 5. Results showed that various MWs of CS NPs significantly reduced the parasite load in the test group, compared to that in negative control group $(P<0.001)$. Growth inhibition rates of tachyzoites in mice receiving LMW, MMW and HMW CS NPs were found to be $86 \%, 84 \%$ and $79 \%$, respectively, compared to mice in sulfadiazine treated group (positive control). The positive control represented $99.8 \%$ of the growth inhibition. No significant differences were seen in anti-Toxoplasma activity between LMW and MMW CS NPs. However, differences were statistically significant for antiToxoplasma activity of HMW CS NPs $(P=0.002)$.

\section{Discussion}

Treatment of toxoplasmosis is often based on a combination of sulfadiazine and pyrimethamine. The limited efficiency of these drugs and the microbial tolerance to them urged further research to find novel therapeutic agents. ${ }^{28}$ In recent years, formulation of novel antimicrobial agents with natural origins such as those from traditional medicinal plants has included nearly $25 \%$ of the currently prescribed synthetic drugs. ${ }^{29} \mathrm{CS}$, one of the novel antimicrobial agents, is a natural and nontoxic compound that has been studied as an effective antimicrobial agent in various forms (eg, solution, film and composite) and used in several in vitro and in vivo experiments against a wide range of microorganisms such as bacteria, fungi, yeasts and algae. ${ }^{12,30}$ Early studies on antimicrobial potency of chitin, CS and other derivatives were recorded from 1980 s to 1990 s. $^{12}$ Recently, CS has been subjected to many research studies due to its strong and advantageous antimicrobial features. ${ }^{31} \mathrm{CS}$ has been reported to be safe for inclusion in various foods used by humans and animals in different countries like Japan, Italy and Finland. Furthermore, it has been approved by the US Food and Drug Administration (FDA) for use in wound dressings. ${ }^{11}$

CS has been recognized as safe for use as food additives in humans and animals in a study conducted in Japan. Researchers have shown that CS-containing gums are more efficient than mouth washes in the prevention of oral bacterial growth in saliva. ${ }^{32}$ Other studies have shown that chewing CS-containing gums effectively inhibits cariogenic bacterial growth (eg, total bacteria, total streptococci and mutant streptococci) in saliva. ${ }^{33}$ The antimicrobial potency of CS 

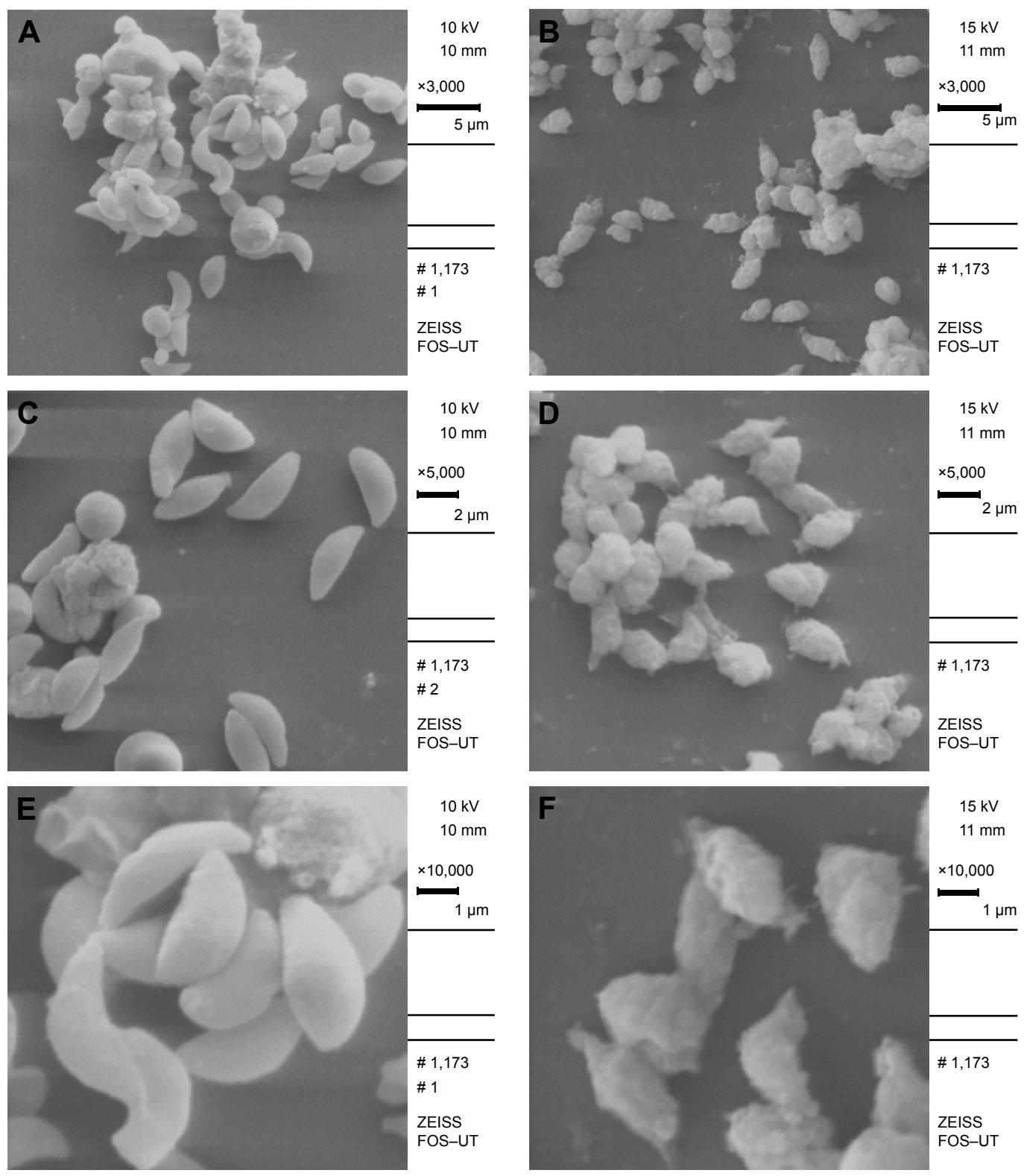

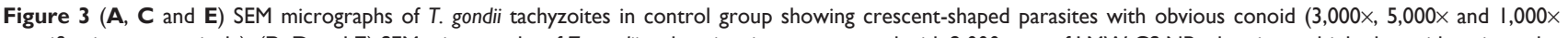
magnification, respectively). (B, D and F) SEM micrographs of $T$. gondii tachyzoites in group treated with 2,000 Ppm of LMW CS NPs showing multiple deep ridges, irregular papules and large projections on the surface $(3,000 \times, 5,000 \times$ and I,000× magnification, respectively).

Abbreviations: SEM, scanning electron microscopy; LMW CS NPs, low molecular weight chitosan nanoparticles; T. gondii, Toxoplasma gondii.

has recently been extended to include parasitic infections. Various concentrations of CS exhibited significant effects on Plasmodium berghei in mice treatment group, compared to those in mice control group. ${ }^{34}$ Similar studies have shown that $1.250 \mu \mathrm{g} / \mathrm{mL}$ of CS after $360 \mathrm{~min}$ and $400 \mu \mathrm{g} / \mathrm{mL}$ of the component after 180 min of exposure completely inhibit the viability of Trichomonas gallinae trophozoites and Giardia lamblia cysts, respectively. ${ }^{35,36}$

To improve the therapeutic efficiency, NPs have been used widely as vehicles to deliver drugs or vaccines in previous studies. ${ }^{7,910,14}$ However, a few studies have been carried out to evaluate the effects of NPs on parasitic infections. For example, NPs have been increasingly introduced as trial agents in toxoplasmosis. ${ }^{37}$ These components have been assessed in helminthic parasites such as Brugia malayi and in parasitic protozoa such as Leishmania major, Plasmodium spp. and T. gondii. ${ }^{38-41}$ Furthermore, NPs such as CS, curcumin and Ag-NPs have been used in in vivo treatment of giardiasis in experimental models. Combinations of Ag and CS NPs have been shown to provide the best results in parasitic infection treatments. ${ }^{42}$ CS NPs have been used as a new delivery system for many antiparasitic drugs and as a novel pharmacological 
Table 4 Effects of various MWs of CS NPs on survival time of mice infected by $T$. gondii $\mathrm{RH}$ strain tachyzoites

\begin{tabular}{|c|c|c|c|}
\hline \multirow[t]{3}{*}{ Group } & \multicolumn{3}{|l|}{ Mean } \\
\hline & \multirow{2}{*}{$\begin{array}{l}\text { Mean survival } \\
\text { time (days) } \\
\pm \text { SD }\end{array}$} & \multicolumn{2}{|l|}{$95 \% \mathrm{Cl}$} \\
\hline & & $\begin{array}{l}\text { Lower bound } \\
\text { (days) }\end{array}$ & $\begin{array}{l}\text { Upper bound } \\
\text { (days) }\end{array}$ \\
\hline LMW of CS NPs & $7 \pm 0.4^{*}$ & 6.1 & 7.8 \\
\hline MMW of CS NPs & $5.4 \pm 0.4$ & 4.6 & 6.1 \\
\hline HMW of CS NPs & $5.4 \pm 0.2$ & 4.9 & 5.8 \\
\hline Negative control & $4.7 \pm 0.3$ & 4.0 & 5.5 \\
\hline
\end{tabular}

Notes: *Compared to negative control, $P<0.05$; negative control, normal saline with $1 \%(w / v)$ acetic acid.

Abbreviations: MWs, molecular weights; CS NPs, chitosan nanoparticles; LMW, low molecular weight; MMW, medium molecular weight; HMW, high molecular weight; SD, standard deviation; T. gondii, Toxoplasma gondii.

tool for the treatment of Leishmania infantum, Plasmodium falciparum and Cryptosporidium parvum. The use of these NPs has reduced the required doses and lowered the toxic side effects of the conventional drugs. ${ }^{43-45}$

In the current study, in vitro experiments have demonstrated that various MWs of CS NPs in various concentrations are highly effective against $T$. gondii tachyzoites in all the treated groups. The anti-Toxoplasma effect of various MWs of CS NPs was statistically significant in treated groups, compared to that in the negative control group, at all exposure times and concentrations. Moreover, results of this study have shown that various MWs of CS NPs significantly decreased the parasite load in peritoneal exudates from the treated mice,

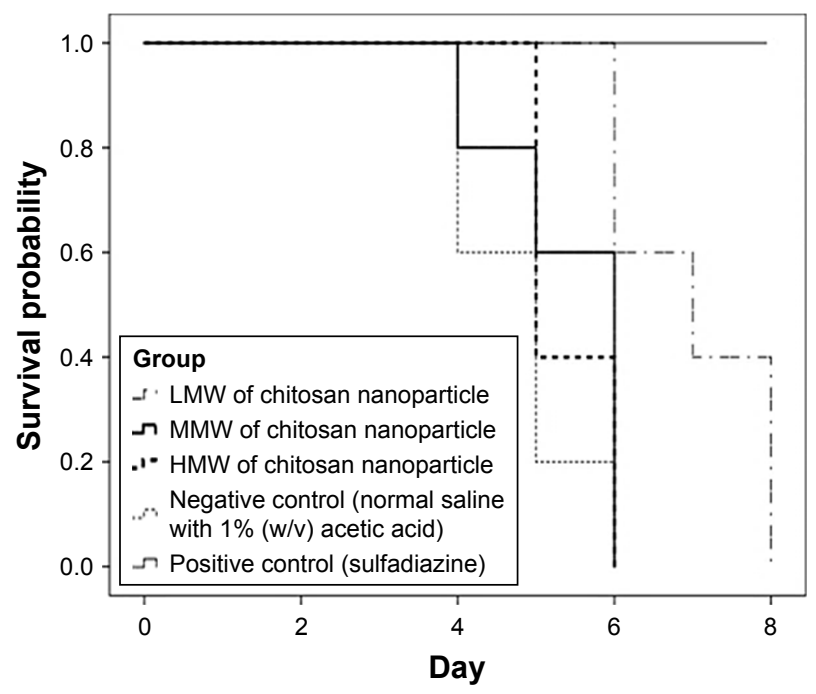

Figure 4 Effects of various MWs of CS NPs on survival time of BALB/c mice infected by $\mathrm{I} \times 10^{4}$ tachyzoites of $T$. gondii RH strain. Treatment was carried out for 5 days and initiated $4 \mathrm{~h}$ after inoculation. Results were evaluated using Kaplan-Meier product limit method.

Abbreviations: MWs, molecular weights; CS NPs, chitosan nanoparticles; LMW, low molecular weight; MMW, medium molecular weight; HMW, high molecular weight; T. gondii, Toxoplasma gondii.
Table 5 Anti-Toxoplasma activities of various MWs of CS NPs in mice peritoneal exudates infected with $\mathrm{I} \times 10^{4}$ tachyzoites of T. gondii RH strain

\begin{tabular}{lll}
\hline Group & $\begin{array}{l}\text { Tachyzoite no } \\
\left(\times 10^{3}\right) \pm \mathbf{S D}\end{array}$ & $\begin{array}{l}\text { \% of growth } \\
\text { inhibition }^{\mathrm{a}}\end{array}$ \\
\hline LMW of CS NPs & $7,200 \pm 105^{\mathrm{b}}$ & 86 \\
MMW of CS NPs & $8,640 \pm 91^{\mathrm{b}}$ & 84 \\
HMW of CS NPs & $10,840 \pm 126^{\mathrm{b}}$ & 79 \\
Positive control $^{\mathrm{c}}$ & $9.8 \pm 1.7$ & 99.8 \\
Negative control $^{\mathrm{d}}$ & $51,000 \pm 250$ & - \\
\hline
\end{tabular}

Notes: apercentage of growth inhibition $=(\mathrm{I}-$ No of tachyzoites after treatment $/$ No of tachyzoites in negative control $) \times 100$; bindication of statistically significant differences compared to negative control $(P<0.001)$; ' sulfadiazine; ${ }^{d}$ normal saline containing $1 \%(\mathrm{w} / \mathrm{v})$ acetic acid.

Abbreviations: MWs, molecular weights; CS NPs, chitosan nanoparticles; LMW, low molecular weight; MMW, medium molecular weight; HMW, high molecular weight; SD, standard deviation; T. gondii, Toxoplasma gondii.

compared to that from negative control mice. However the exact mechanism underlying the antimicrobial activity of chitin, CS and other derivatives is not completely understood; however, various mechanisms have been suggested. One of the most reliable antimicrobial mechanisms includes the interaction between positively charged amino groups at C-2 position of 2-amino-2-deoxy- $\beta$-d-glucopyranose residue of CS and either 1) negatively charged microbial cell membrane components such as phospholipids or proteins; 2) amino acids in the Gram-positive bacterial cell wall; or 3) various lipopolysaccharides (LPS) in the outer membrane of Gram-negative bacteria providing hydrophilic surface for the bacteria. This enhances the permeability of the cell membrane and causes the leakage of cellular contents and hence ultimately leads to cell inhibition/killing. CS inhibits the formation of mRNA and synthesis of various proteins after penetration into the nuclei. Binding to microbial DNA, chelation of metals, suppression of spore elements and binding to essential nutrients required for microbial growth are some other suggested mechanisms. ${ }^{46}$

Studies have demonstrated that the biological activity of CS depends significantly on the component's MW and DD. Although it has been recommended that the effect of MW is greater than that of DD on antimicrobial activity, both factors affect the antimicrobial activity of CS independently. ${ }^{47}$ It has been proven that CS with a lower MW exhibits a stronger effect on the reduction of microorganism growth and multiplication in bacteria such as Escherichia coli, Staphylococcus aureus, Pseudomonas aeruginosa, Salmonella enterica, Bacillus cereus, Bacillus subtilis, Klebsiella pneumonia and Listeria monocytogenes. ${ }^{12}$ The fundamental parameters that contribute to better understanding of the effectiveness of LMW CS include size and conformation. 
The adoption of an extended conformation and effective binding to the membrane surface are more facilitating in small chains than in long chains due to better mobility, attraction and ionic interaction. ${ }^{48}$ In contrast, it has been demonstrated that CS with MW less than $2.2 \mathrm{kDa}$ shows low impacts on bacterial growth. Moreover, the minimum inhibitory concentration of CS oligomers included values smaller than $0.004 \%$ and $0.032 \%$ for MWs of 9.3 and $5.5 \mathrm{kDa}$, respectively. ${ }^{19} \mathrm{CS}$ with $\mathrm{MW}$ of $40 \mathrm{kDa}$ has been reported to inhibit the growth of $S$. aureus and $E$. coli by nearly $90 \%$ in concentrations of $0.5 \%$, while CS with MW of $180 \mathrm{kDa}$ could completely inhibit the growth of these bacteria at the same concentration. ${ }^{49}$ In the present study, various MWs of CS NPs at various concentrations were studied for the first time as therapeutic agents against experimental toxoplasmosis in vitro and in vivo. Despite several studies on antibacterial, antiviral and antifungal activities of CS with various MWs, no study has been carried out on effects of various MWs of CS NPs on T. gondii tachyzoites. Results have shown that the anti-Toxoplasma activity of CS NPs increased as the MW decreased. In general, LMW CS NPs have been shown to exhibit a greater effectiveness on T. gondii tachyzoites than MMW and HMW CS NPs. This may be due to size and conformation of CS NPs as well as their MW that facilitate ionic interaction and enhance the cellular uptake, mobility and attraction, thus enabling them to effectively bind to membrane surface of tachyzoites. The LMW CS NPs showed the most potential anti-Toxoplasma activity, while MMW and HMWCS NPs showed approximately equal effects on the parasite activity which could be due to degradation and conversion of HMW CS into LMW CS, which normally occurs in HMW CS. In the current study, LMW CS showed a higher DD than shown by MMW CS and HMW CS. CS with high DD has been shown to be more effective in bacterial growth inhibition than that with low DD, possibly due to a higher proportion of protonated amine groups. ${ }^{46}$

To verify the results of the present study, SEM was performed on the parasite tachyzoites after $2 \mathrm{~h}$ of exposure to LMW CS NPs. ${ }^{50}$ Control tachyzoites demonstrated intact plasma membranes and stable outer cell walls uniformed within the entire cell perimeter. Tachyzoites treated with CS NPs showed irregular structures and multiple deep ridges on the cell surface, which may be due to the CS deposits that might still be attached to negatively charged surface polymers. The electrostatic interaction between positively charged CS molecules and outer membrane components of tachyzoites, including phospholipids and proteins with negative charges, causes changes in integrity and permeability of the cell wall. These changes can lead to leakage of proteinaceous constituents and other cell contents. Moreover, penetration of CS molecules into the nuclei and binding of these molecules with the parasite DNA possibly inhibit the formation of mRNA and DNA transcription. In 1992, Hammouda et al showed that changes in the shape of microorganisms might be secondary changes resulting from the interference of drugs with parasite DNA synthesis or folic acid cycle.$^{51}$ In addition, treatment of $T$. gondii infected mice with various MWs of CS NPs prolonged the survival of the animals, and statistically significant differences were seen in the survival of mice treated with LMW of CS NPs, compared to that of mice in control group.

\section{Conclusion}

Results from the current study have shown that various MWs of CS NPs with various concentrations exhibit potential antiToxoplasma activities; however, the LMW CS NPs with a MW of $86 \pm 4.1 \mathrm{kDa}$ and $82 \% \pm 0.6 \%$ DD show the greatest activity against $T$. gondii tachyzoites in both in vitro and in vivo experiments. The CS NPs can be used as suitable alternative natural medicine to eliminate $T$. gondii infection owing to its low toxicity and considerable inhibition potency of the infection. Since NPs have been widely used as vehicles for drug delivery and due to the abovementioned results, use of CS NPs with routine anti-parasitic drugs such as pyrimethamine or sulfadiazine is suggested.

\section{Acknowledgments}

This study was supported by the Tehran University of Medical Sciences and Health Services (Project Numbers: 95-03-61-32426 and 95-04-61-33436), Tehran, Iran. We would like to acknowledge all staff from the toxoplasmosis laboratory (Department of Medical Parasitology and Mycology, Tehran University of Medical Sciences, Tehran, Iran) for their useful collaboration.

\section{Disclosure}

The authors report no conflicts of interest in this work.

\section{References}

1. Dubey JP. Toxoplasmosis of Animals and Humans. 2nd ed. New York: Boca Raton; 2010:1-313.

2. Tenter AM, Heckeroth AR, Weiss LM. Toxoplasma gondii: from animals to humans. Int J Parasitol. 2000;30:1217-1258.

3. Tuazon CU. Toxoplasmosis in AIDS patients. J Antimicrob Chemother. 1989;23:77-82.

4. Rostami A, Keshavarz H, Shojaee S, Mohebali M, Meamar AR Frequency of Toxoplasma gondii in HIV positive patients from west of Iran by ELISA and PCR. Iran J Parasitol. 2014;9:474-481. 
5. SharbatkhoriM, Moghaddam YD, Pagheh AS, Mohammadi R, MofidiHH, Shojaee S. Seroprevalence of Toxoplasma gondii infections in pregnant women in Gorgan City, Golestan Province, Northern Iran. Iran J Parasitol. 2014;9:181-187.

6. Martins-Duarte ES, Urbina JA, Souza W, Vommaro RC. Antiproliferative activities of two novel quinuclidine inhibitors against Toxoplasma gondii tachyzoites in vitro. J Antimicrob Chemother. 2006;58: $59-65$.

7. Khan I, Khan M, Umar MN, Oh DH. Nanobiotechnology and its applications in drug delivery system: a review. IET Nanobiotechnol. 2015;9:396-400.

8. Hosseinnejad M, Jafari SM, Katouzian I. Inorganic and metal nanoparticles and their antimicrobial activity in food packaging applications. Crit Rev Microbiol. 2017;1-21.

9. Angeli E, Buzio R, Firpo G, et al. Nanotechnology applications in medicine. Tumori. 2008;94:206-215.

10. Debbage P. Targeted drugs and nanomedicine: present and future. Curr Pharm Des. 2009;15:153-172.

11. Kean T, Thanou M. Biodegradation, biodistribution and toxicity of chitosan. Adv Drug Deliv Rev. 2009;62:3-11.

12. Goy RC, De Britto D, Assis OBG. A review of the antimicrobial activity of chitosan. Polimeros. 2009;19:241-247.

13. De Marchi JG, Jornada DS, Silva FK, et al. Triclosan resistance reversion by encapsulation in chitosan-coated-nanocapsule containing $\alpha$-bisabolol as core: development of wound dressing. Int J Nanomedicine. 2017;12: $7855-7868$

14. Wang JJ, Zeng ZW, Xiao RZ, et al. Recent advances of chitosan nanoparticles as drug carriers. Int J Nanomedicine. 2011;6:765-774.

15. Hosseinnejad M, Jafari SM. Evaluation of different factors affecting antimicrobial properties of chitosan. Int J Biol Macromol. 2016;85: 467-475.

16. Jeon YJ, Park PJ, Kim SK. Antimicrobial effect of chitooligosaccharides produced by bioreactor. Carbohydr Polym. 2001;44:71-76.

17. Jeon YJ, Kim SK. Production of chitooligosaccharides using an ultrafiltration membrane reactor and their antibacterial activity. Carbohydr Polym. 2000;41:133-144.

18. No HK, Park NY, Lee SH, Meyers SP. Antibacterial activity of chitosans and chitosan oligomers with different molecular weights. Int $J$ Food Microbiol. 2002;74:65-72.

19. Ueno K, Yamaguchi T, Sakairi N, Nishi N, Tokura S. Antimicrobial activity by fractionated chitosan oligomers. In: Domard A, Roberts GAF, Varum KM, editors. Advances in Chitin Science (II). Lyon, France: Jacques Andre; 1997:156-161.

20. Ali-Heydari S, Keshavarz H, Shojaee S, Mohebali M. Diagnosis of antigenic markers of acute toxoplasmosis by IgG avidity immunoblotting. Parasite. 2013;20:20-18.

21. Jiang TD. Chitosan. Beijing, China: Chemical Industry Press; 2001:91, $100,108$.

22. Lewandowska K. Viscometric studies in dilute solution mixtures of chitosan and microcrystalline chitosan with poly(vinyl alcohol). J Solution Chem. 2013;42:1654-1662.

23. Koukaras EN, Papadimitriou SA, Bikiaris DN, Froudakis GE. Insight on the formation of chitosan nanoparticles through ionotropic gelation with tripolyphosphate. Mol Pharm. 2012;9:2856-2862.

24. Dzitko K, Paneth A, Plech T, et al. 1, 4-disubstituted thiosemicarbazide derivatives are potent inhibitors of Toxoplasma gondii proliferation. Molecules. 2014;19:9926-9943.

25. Burg JL, Grover CM, Pouletty P, Boothroyd JC. Direct and sensitive detection of a pathogenic protozoan, Toxoplasma gondii, by polymerase chain reaction. J Clin Microbiol. 1989;27:1787-1792.

26. Jeroen PJ, Saeij JP, Boyle ME, Grigg GA, Boothroyd JC. Bioluminescence imaging of Toxoplasma gondii infection in living mice reveals dramatic differences between strains. Infect Immun. 2005;73:695-702.

27. Fletcher RH, Fletcher SW, Wagner EH. Clinical Epidemiology: The Essentials. 3rd ed. Baltimore: Williams and Wilkins; 1996.
28. Shubar HM, Lachenmaier S, Heimesaat MM, et al. SDS-coated atovaquone nanosuspensions show improved therapeutic efficacy against experimental acquired and reactivated toxoplasmosis by improving passage of gastrointestinal and blood-brain barriers. J Drug Target. 2011:19:114-124.

29. Cowan MM. Plant products as antimicrobial agents. Clin Microbiol Rev. 1999;12:564-582.

30. Verlee A, Mincke S, Stevens CV. Recent developments in antibacterial and antifungal chitosan and its derivatives. Carbohydr Polym. 2017;164:268-283.

31. Kong M, Chen XG, Xing K, Park HJ. Antimicrobial properties of chitosan and mode of action: a state of the art review. Int J Food Microbiol. 2010;144:51-63.

32. Hayashi Y, Ohara N, Ganno T, Ishizaki H, Yanagiguchi K. Chitosan containing gum chewing accelerates antibacterial effect with an increase in salivary secretion. $J$ Dent. 2007;35:871-874.

33. Hayashi $Y$, Ohara N, Ganno T, et al. Chewing chitosan-containing gum effectively inhibits the growth of cariogenic bacteria. Arch Oral Biol. 2007;52:290-294.

34. Teimouri A, Motevalli Haghi A, Nateghpour M, et al. Antimalarial efficacy of low molecular weight chitosan against Plasmodium berghei infection in mice. J Vector Borne Dis. 2016;53:312-316.

35. Tavassoli M, Imani A, Tajik H, Moradi M, Pourseyed SH. Novel in vitro efficiency of chitosan biomolecule against Trichomonas gallinae. Iran J Parasitol. 2012;7:92-96.

36. Yarahmadi M, Fakhar M, Ebrahimzadeh MA, Chabra A, Rahimi-esboei B. The anti-giardial effectiveness of fungal and commercial chitosan against Giardia intestinalis cysts in vitro. J Parasit Dis. 2016;40:75-80.

37. Prieto MJ, Bacigalupe D, Pardini O, et al. Nanomolar cationic dendrimeric sulfadiazine as potential antitoxoplasmic agent. Int J Pharmcol. 2006;326:160-168.

38. Ali M, Afzal M, Verma M, Misra-Bhattacharya S, Ahmad FJ, Dinda AK. Improved antifilarial activity of ivermectin in chitosan-alginate nanoparticles against human lymphatic filarial parasite, Brugia malayi. Parasitol Res. 2013;112:2933-2943.

39. Danesh-Bahreini MA, Shokri J, Samiei A, Kamali-Sarvestani E, Barzegar-Jalali M, Soliman MS. Nanovaccine for leishmaniasis: preparation of chitosan nanoparticles containing leishmania superoxide dismutase and evaluation of its immunogenicity in BALB/c mice. Int J Nanomedicine. 2011;6:835-842.

40. Jiang S, Hua E, Liang M, Liu B, Xie G. A novel immunosensor for detecting Toxoplasma gondii-specific IgM based on goldmag nanoparticles and grapheme sheets. Colloids Surf B Biointerfaces. 2013;101:481-486.

41. Tripathy S, Das S, Chakraborty SP, Sahu SK, Pramanik P, Roy S. Synthesis, characterization of chitosan-tripolyphosphate conjugated chloroquine nanoparticle and its in vivo anti-malarial efficacy against rodent parasite: a dose and duration dependent approach. Int J Pharmacol. 2012;434:292-305.

42. Said DE, ElSamad LM, Gohar YM. Validity of silver, chitosan and curcumin nanoparticles as anti-giardia agents. Parasitol Res. 2012;111:545-554.

43. Föger F, Noonpakdee W, Loretz B, et al. Inhibition of malarial topoisomerase II in Plasmodium falciparum by antisense nanoparticles. Int J Pharm. 2006;319:139-146.

44. Kayser O. A new approach for targeting to Cryptosporidium parvum using mucoadhesive nanosuspensions. Res Appl. 2001;214:83-85.

45. Pujals G, Sune-Negre JM, Pérez P, et al. In vitro evaluation of the effectiveness and cytotoxicity of meglumine antimoniate microspheres produced by spray drying against Leishmania infantum. Parasitol Res. 2008;102:1243-1247.

46. Raafat D, Sahl HG. Chitosan and its antimicrobial potential - a critical literature survey. Microb Biotechnol. 2009;2:186-201.

47. Sekiguchi S, Miura Y, Kaneko H, et al. Molecular weight dependency of antimicrobial activity by chitosan oligomers. In: Nishinari K, Doi E, editors. Food Hydrocolloids: Structures, Properties and Functions. New York: Plenum Press; 1994. 
48. Kumar ABV, Varadaraj MC, Gowda LR, Tharanathan RN. Characterization of chito-oligosaccharides prepared by chitosanolysis with the aid of papain and pronase, and their bactericidal action against Bacillus cereus and Escherichia coli. Biochem J. 2005;391: 167-175.

49. Shin Y, Min K, Kim HK. Antimicrobial finishing of polypropylene nonwoven fabric by treatment with chitosan. In: Domard A, Roberts GAF, Varum KM, editors. Advances in Chitin Science. Vol II. Lyon, France: Jacques Andre Publisher; 1997:771-778.
50. El-Tombary AA, Ismail KA, Aoulwafa OM, Omar AME, El-Azzouni MZ, El-Mansoury ST. Novel triazolo(4,3-a)quinazoline and bis-triazolo(4,3-a: 4,3-c)quinazolines: synthesis and antitoxoplasmosis effect. II Farmaco. 1999;54:486-495.

51. Hammouda NA, El-Mansoury ST, El-Azzouni MZ. Toxoplasma gondii: scanning electron microscopic study before and after treatment. J Trop Med. 1992;2:77-83.
International Journal of Nanomedicine

\section{Publish your work in this journal}

The International Journal of Nanomedicine is an international, peerreviewed journal focusing on the application of nanotechnology in diagnostics, therapeutics, and drug delivery systems throughout the biomedical field. This journal is indexed on PubMed Central, MedLine, CAS, SciSearch $®$, Current Contents $® /$ Clinical Medicine,

\section{Dovepress}

Journal Citation Reports/Science Edition, EMBase, Scopus and the Elsevier Bibliographic databases. The manuscript management system is completely online and includes a very quick and fair peer-review system, which is all easy to use. Visit http://www.dovepress.com/ testimonials.php to read real quotes from published authors.

Submit your manuscript here: http://www.dovepress.com/international-journal-of-nanomedicine-journal 